\title{
The Yersinia pestis autotransporter YapC mediates host cell binding, autoaggregation and biofilm formation
}

Correspondence

Eric S. Krukonis

ekrukoni@umich.edu

Received 20 June 2007

Revised 31 January 2008

Accepted 5 March 2008
Suleyman Felek, ${ }^{1}$ Matthew B. Lawrenz ${ }^{2}$ and Eric S. Krukonis ${ }^{1,3}$

${ }^{1}$ Department of Biologic and Materials Sciences, University of Michigan School of Dentistry, Ann Arbor, MI 48109-1078, USA

${ }^{2}$ Department of Molecular Microbiology, Washington University School of Medicine, St Louis, MO 63110, USA

${ }^{3}$ Department of Microbiology and Immunology, University of Michigan School of Medicine, Ann Arbor, Ml 48109-0620, USA

YapC, a putative Yersinia pestis autotransporter protein, shows strong homology to the enterotoxigenic Escherichia coli adhesin TibA. As a potentially important surface protein of $Y$. pestis, we analysed YapC for several activities. When expressed in the non-pathogenic Fim $^{-} E$. coli strain AAEC185, YapC mediated attachment to both murine-derived macrophage-like cells (RAW264.7) and human-derived epithelial-like cells (HEp-2). In addition, expression of YapC on the surface of $E$. coli led to autoaggregation in DMEM tissue culture medium, a phenomenon associated with virulence in Yersinia species. YapC also mediated formation of biofilm-like deposits by $E$. coli AAEC185. Deletion of yapC in $Y$. pestis strain KIM5 resulted in no change in adhesion to either RAW264.7 or HEp-2 cells, or in biofilm formation. Lack of a phenotype for the $Y$. pestis $\triangle y a p C$ mutant may reflect the relatively low level of yapC expression in vitro, as assessed by RT-PCR, and/or redundant functions expressed in vitro. These data demonstrate several activities for YapC that may function during $Y$. pestis infection.

\section{INTRODUCTION}

Yersinia pestis, the causative agent of plague, is a Gramnegative pathogen that evolved from the enteric pathogen Yersinia pseudotuberculosis as recently as 1500 years ago (Achtman et al., 1999). Plague is one of the most deadly infectious diseases in history, killing $\sim 25 \%$ of the population of Western Europe during the years 13471351 (Cantor, 2001; Perry \& Fetherston, 1997).

To efficiently establish infection, bacteria express a variety of adhesins on their surface. While a number of Yersinia adhesins have been extensively studied, some of the bestcharacterized adhesins of $Y$. pseudotuberculosis and Yersinia enterocolitica are not expressed in $Y$. pestis. These include invasin (Isberg et al., 1987; Rosqvist et al., 1990) and YadA (Rosqvist et al., 1990; Tamm et al., 1993; Yang \& Isberg, 1993), which have been mutated by IS 100 element insertion and frameshift mutation, respectively (Deng et al., 2002; Parkhill et al., 2001).

Abbreviations: ETEC, enterotoxigenic E. coli; FCS, fetal calf serum; T3SS, type III secretion system.

A supplementary table of primers is available with the online version of this paper.
Two known adhesins that are expressed by $Y$. pestis are pH 6 antigen and plasminogen activator. pH 6 antigen (encoded by $p s a A$ ) was first described as a surface component of $Y$. pestis induced at temperatures $\geqslant 35{ }^{\circ} \mathrm{C}$ and $\mathrm{pH} \leqslant 6.7$ (Ben-Efraim et al., 1961) that forms $4 \mathrm{~nm}$ thick fibrils on the bacterial surface (Lindler \& Tall, 1993). In addition, pH 6 antigen acts as an adhesin for cultured cells and agglutinates red blood cells from several animal species (Bichowsky-Slomnicki \& Ben-Efraim, 1963; Yang et al., 1996). Plasminogen activator (Pla) also mediates $Y$. pestis adhesion to eukaryotic cells and extracellular matrix (Kienle et al., 1992; Lahteenmaki et al., 1998). Pla is localized on the outer membrane of $Y$. pestis and cleaves and activates plasminogen to facilitate bacterial dissemination from peripheral tissues to other organs (Beesley et al., 1967; Sodeinde et al., 1992; Welkos et al., 1997). It has also been reported to be an invasin for Y. pestis (Cowan et al., 2000; Lahteenmaki et al., 2001).

One of the hallmarks of $Y$. pestis infection is the delivery of cytotoxic Yop proteins from the bacterium to the host cell cytoplasm via a type III secretion system (T3SS; Cornelis et al., 1998), a process that requires adhesion to the host cell (Rosqvist et al., 1990). The fact that adhesins in addition to the T3SS translocators, YopB and YopD of Yersinia species, are required for Yop delivery was 
demonstrated using an uncharacterized non-adherent derivative of $Y$. pestis strain EV76, in which Yop-mediated cytotoxicity was restored upon expression of the adhesins invasin or YadA of Y. pseudotuberculosis (Rosqvist et al., 1990). However, Y. pestis strains defective for $\mathrm{pH} 6$ antigen (Lindler et al., 1990) or plasminogen activator (Brubaker et al., 1965) can still mediate Yop delivery to host cells, as measured by maintenance of virulence. Thus, additional adhesins of $Y$. pestis are predicted to mediate the cell adhesion required for Yop delivery and other virulenceassociated events.

To identify additional $Y$. pestis adhesins that are potentially important for virulence, we investigated the role of the annotated $Y$. pestis autotransporter protein YapC, a homologue (33.7\% identity) of TibA, an adhesin/invasin of enterotoxigenic Escherichia coli (ETEC) (Lindenthal \& Elsinghorst, 2001).

Autotransporters are characterized by the presence of an Nterminal 'passenger' domain, which can possess an array of functions, and a C-terminal translocation domain that forms a $\beta$-barrel allowing secretion of the passenger domain to the cell surface (Henderson et al., 2004). Some autotransporters remain intact on the cell surface, while others can be cleaved by a variety of mechanisms, including cleavage by an endogenous protease activity in the passenger domain (Hendrixson et al., 1997), cleavage by a different protease in the bacterial cell (Egile et al., 1997; Shere et al., 1997) or a recently characterized intramembrane self-cleavage mechanism within the $\beta$-barrel structure (Dautin et al., 2007). Neither TibA nor YapC appear to direct their own cleavage via a passenger-domain-mediated protease activity
(Elsinghorst \& Weitz, 1994; Lindenthal \& Elsinghorst, 2001; Yen et al., 2007), and residues required for the newly discovered intramembrane self-cleavage mechanism are lacking in both TibA and YapC (Dautin et al., 2007). YapC is also predicted to belong to the AT-1 family of monomeric autotransporters (Yen et al., 2007).

TibA of E. coli is a glycosylated surface protein and glycosylation is required for its cell-binding activity (Sherlock et al., 2005). In the case of TibA, the glycosylating enzyme, TibC, is encoded immediately upstream of tibA within the same operon. In the case of YapC, genome analysis revealed no neighbouring glycosylating enzyme homologue, although this does not exclude the possibility that YapC is glycosylated.

In addition to mediating adhesion and invasion of epithelial cells, TibA enhances biofilm formation and autoaggregation in ETEC (Sherlock et al., 2005). We demonstrate here that YapC of Y. pestis mediates adhesion of recombinant $E$. coli to murine macrophages and human epithelial cells. YapC also facilitates E. coli autoaggregation and formation of biofilm-like deposits. Recent studies also found that YapC was surface localized when expressed in $E$. coli and that it could mediate autoaggregation (Yen et al., 2007). These activities may be important for colonization, survival or transmission during $Y$. pestis infections.

\section{METHODS}

Bacterial strains, plasmids and tissue culture cells. Characteristics and sources of the bacterial strains and plasmids used in this study are listed in Table 1. Gene deletions in Y. pestis KIM5

Table 1. Bacterial strains and plasmids used in this study

\begin{tabular}{|c|c|c|}
\hline Strain or plasmid & Genotype or features & Reference or source \\
\hline \multicolumn{3}{|l|}{ E. coli } \\
\hline AAEC185 & supE44 hsdR17 mcrA mcrB endA1 thi-1 $\Delta$ fimB-fimH $\Delta$ recA & Blomfield et al. (1991) \\
\hline KIM5-3001 (referred to as KIM5) & KIM5-3001, Pgm $^{-}$, Str $^{\mathrm{r}}$ & Laboratory collection \\
\hline KIM5-3001- $\Delta p s a A$ & KIM5-3001 $\Delta p s a A$ & This study \\
\hline KIM5-3001- $\Delta y a p C$ & KIM5-3001 $\Delta y a p C$ & This study \\
\hline KIM5-3001- $\Delta$ caf1 & KIM5-3001 $\Delta c a f 1$ & This study \\
\hline KIM5-3001- $\Delta$ caf1 $1 \Delta y a p C$ & KIM5-3001 $\Delta \mathrm{caf} 1 \Delta y a p C$ & This study \\
\hline KIM5-3001- $\Delta$ caf1 $1 \Delta p s a A$ & KIM5-3001 $\Delta c a f 1 \Delta p s a A$ & This study \\
\hline KIM5-3001- $\Delta c a f 1 \Delta y a p C \Delta p s a A$ & KIM5-3001 $\Delta \mathrm{caf} 1 \Delta y a p C \Delta p s a A$ & This study \\
\hline KIM5-3001 pCD1- & KIM5-3001 pCD1 ${ }^{-}, \mathrm{Pgm}^{-}, \mathrm{Str}^{\mathrm{r}}$ & This study \\
\hline KIM8-3002 - n & KIM5 pPCP1 ${ }^{-}\left(\mathrm{Pla}^{-}\right) \mathrm{Pgm}^{-}, \mathrm{Str}^{\mathrm{r}}$ & Laboratory collection \\
\hline pMMB207-yapC & $11.0 \mathrm{~kb}, \mathrm{Cm}^{\mathrm{r}}$ & This study \\
\hline pKD46 & $6.3 \mathrm{~kb}, \mathrm{Amp}^{\mathrm{r}}$, RED recombinase expression plasmid & Datsenko \& Wanner (2000) \\
\hline pKD4 & $3.3 \mathrm{~kb}, \mathrm{Km}^{\mathrm{r}}$, template plasmid & Datsenko \& Wanner (2000) \\
\hline pCP20 & $9.4 \mathrm{~kb}$, Flp recombinase expression plasmid, $\mathrm{Amp}^{\mathrm{r}} \mathrm{Cm}^{\mathrm{r}}$ & Datsenko \& Wanner (2000) \\
\hline
\end{tabular}


were performed using PCR products and the method described by $\mathrm{Yu}$ et al. (2000) and Datsenko \& Wanner (2000). Briefly, the pKD4 kanamycin-resistance cassette was amplified by PCR with primers having $5^{\prime}$ extension sequences from regions flanking the gene(s) targeted for deletion. Input template DNA in the PCR reaction was digested with $D p n \mathrm{I}$, and the $D p n \mathrm{I}$-resistant PCR product was transformed into $Y$. pestis KIM5 that had been previously transformed with pKD46, encoding the $\lambda$-RED recombinase, and induced for $4-$ $5 \mathrm{~h}$ with $10 \mathrm{mM}$ arabinose before preparation of electrocompetent cells. Kanamycin-resistant colonies were selected and the deletion(s) confirmed by PCR. The strain was then transformed with pCP20, encoding the FLP recombinase, which resulted in excision of the kanamycin-resistance gene. Plasmids were removed from the strains by growth in heart infusion broth (HIB) without drug selection. All incubations were performed at $28{ }^{\circ} \mathrm{C}$. HEp-2 cells (ATCC CCL-23) were cultured in MEM $+10 \%$ fetal calf serum (FCS) and RAW264.7 macrophages (ATCC TIB-71) were cultured in Dulbecco's modified Eagle's medium DMEM (Gibco) $+10 \%$ FCS.

Cloning of $Y$. pestis loci. For cloning, the genes encoding YapC or PsaABC were amplified from strain KIM5-3001 (referred to as 'KIM5' throughout this study) by PCR using the Expand High Fidelity PCR System (Roche) or Pfu Turbo Taq Polymerase (Stratagene), respectively. PCR products and plasmid pMMB207 (Morales et al., 1991) were cut by appropriate enzymes, gel purified, and the PCR products were ligated into $\mathrm{pMMB207}$. PCR products were designed to include the natural Shine-Dalgarno ribosome-binding site of the gene of interest, but lack the natural promoter. Expression was induced in E. coli with IPTG. E. coli DH5 $\alpha$ was transformed with the ligation products and chloramphenicol-resistant colonies were selected. Clones were confirmed by DNA sequencing. Plasmids were then purified and transformed into the $\mathrm{Fim}^{-}$E. coli strain AAEC185 (Blomfield et al., 1991).

Outer-membrane preparations and SDS-PAGE. E. coli AAEC185 and derivatives were cultured overnight in LB medium supplemented with $10 \mu \mathrm{g}$ chloramphenicol $\mathrm{ml}^{-1}$ and $100 \mu \mathrm{M}$ IPTG at $28{ }^{\circ} \mathrm{C}$ or $37^{\circ} \mathrm{C}$ and outer-membrane preparations were made by the method described by Hantke (1984). Briefly, $1 \mathrm{ml}$ of a $3 \mathrm{ml}$ overnight culture induced with $100 \mu \mathrm{M}$ IPTG was pelleted at $4{ }^{\circ} \mathrm{C}$. Cells were resuspended in $1 \mathrm{ml} 0.2 \mathrm{M}$ Tris/ $\mathrm{HCl}(\mathrm{pH} 8.0)$ and centrifuged again at $4{ }^{\circ} \mathrm{C}$ for $5 \mathrm{~min}$. Cells were resuspended in $50 \mu \mathrm{l} 0.2 \mathrm{M} \mathrm{Tris} / \mathrm{HCl}$ ( $\mathrm{pH} 8.0$ ) and the following were added in order: $100 \mu \mathrm{l} 0.2 \mathrm{M}$ Tris/ $\mathrm{HCl}(\mathrm{pH} 8.0) / 1 \mathrm{M}$ sucrose, $10 \mu \mathrm{l} 10 \mathrm{mM}$ EDTA ( $\mathrm{pH} 8.0$ ), $10 \mu \mathrm{l} 2 \mathrm{mg}$ lysozyme $\mathrm{ml}^{-1}$ and $320 \mu \mathrm{l}$ double-distilled (dd) $\mathrm{H}_{2} \mathrm{O}$. Preparations were mixed and incubated at room temperature for $10 \mathrm{~min}$, then $10 \mu \mathrm{l} 1 \mathrm{mg}$ DNase $\mathrm{ml}^{-1}$ was added and mixed, followed by $500 \mu \mathrm{l} 2 \%$ Triton X-100/10 mM MgCl $/ 200 \mathrm{mM}$ Tris/ $\mathrm{HCl}$ (pH 8.0). Preparations were mixed well and centrifuged at $4{ }^{\circ} \mathrm{C}$ in a microcentrifuge for $30 \mathrm{~min}$ at maximum speed. Supernatants were saved (referred to as

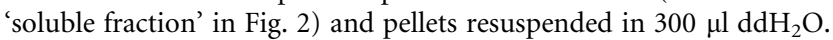
Preparations were then centrifuged at $4{ }^{\circ} \mathrm{C}$ for $15 \mathrm{~min}$, washed twice more with $\mathrm{ddH}_{2} \mathrm{O}$ and resuspended in $100 \mu$ l SDS-PAGE sample buffer and boiled for $5 \mathrm{~min}$. Isolated outer membranes were subjected to SDS-PAGE followed by Coomassie blue staining.

Western blotting. For cell fractionation experiments where extracts were probed with anti-PsaA or anti-RNA polymerase $\alpha$-subunit $(\mathrm{RNAP} \alpha)$ antibodies, cells were grown and processed as described for the outer-membrane preparations. In addition, the extent of shearing of $\mathrm{pH} 6$ antigen (PsaA) filaments from the bacterial surface was assessed by Western blot analysis of culture supernatants. Western blots were probed with a $1: 1000$ dilution of a rabbit anti-PsaA antibody, kindly provided by Dr Susan Straley (Dept of Microbiology, Immunology \& Molecular Genetics, University of Kentucky). Anti-RNIAP $\alpha$ Western blots were probed with a 1:1000 dilution of mouse anti-RNAP $\alpha$ antibody generated against E. coli RNAP $\alpha$ (Neoclone). Blots were washed and probed with anti-rabbit-horeseradish peroxidase (HRP) or anti-mouseHRP secondary antibodies, respectively (Zymed) prior to developing with Supersignal West Pico ECL substrate (Pierce).

Cytotoxicity assay. HEp- 2 cells were grown to $\geqslant 80 \%$ confluency in 24-well tissue culture plates (Falcon, Becton Dickinson) in minimal Eagle's medium (MEM) with Earle's salts and L-glutamine (Gibco) supplemented with $10 \%$ FCS, $1 \%$ non-essential amino acids and $1 \%$ sodium pyruvate. RAW 264.7 cells were cultured until $\geqslant 80 \%$ confluency in 24-well plates containing DMEM (high glucose, with Lglutamine and pyridoxine hydrochloride, without sodium pyruvate) supplemented with $10 \%$ FCS.

Y. pestis KIM5, KIM5 $\mathrm{pCD}^{-}$and different deletion mutants were cultured overnight at $28{ }^{\circ} \mathrm{C}$ in $\mathrm{HIB}(\mathrm{pH} 7.0)$ with shaking. Cultures were diluted to $\mathrm{OD}_{620} 0.15$ in $\mathrm{HIB} \mathrm{pH} 7.0$ and incubated for a further $4 \mathrm{~h}$ at $28{ }^{\circ} \mathrm{C}$ with shaking. The cultures were pelleted and resuspended in tissue culture medium without serum to $\mathrm{OD}_{620} 1.5$ Plates were washed twice with $1 \mathrm{ml}$ serum-free MEM or DMEM and $1 \mathrm{ml}$ medium without serum was added to each well. Then $50 \mu \mathrm{l}$ of resuspended bacteria was added to achieve an m.o.i. of approximately 100 bacteria per cell. Cell morphology was observed for rounding under a phase-contrast microscope every hour for $4 \mathrm{~h}$. Cell rounding is an indication of Yop-mediated cytotoxicity.

Adhesion assay. Twenty-four-well cell culture plates were prepared as described above. E. coli AAEC185 containing pMMB207, pMMB207-yapC or pMMB207-psaABC was cultured overnight $(16 \mathrm{~h})$ at $28{ }^{\circ} \mathrm{C}$ with shaking in Luria-Bertani (LB) medium supplemented with $10 \mu \mathrm{g}$ chloramphenicol $\mathrm{ml}^{-1}$ and $100 \mu \mathrm{M}$ IPTG. Bacterial cultures were centrifuged and the bacteria were resuspended in serum-free MEM or DMEM at $\mathrm{OD}_{600}$ 0.6. Cells were then diluted $1: 100$ into serum-free MEM or DMEM and $100 \mu \mathrm{l}$ aliquots were used to infect 24-well plates seeded overnight with HEp-2 or RAW264.7 cells (after washing the cells twice with serum-free MEM or DMEM) in $500 \mu \mathrm{l}$ MEM or DMEM respectively (an m.o.i. of approximately 13 bacteria per cell). RAW264.7 cells were treated with $5 \mu \mathrm{g}$ cytochalasin $\mathrm{D} \mathrm{ml}^{-1}$ in DMEM for $45 \mathrm{~min}$ prior to addition of bacteria to inhibit actin-dependent macrophage phagocytosis. Plates were incubated at $37{ }^{\circ} \mathrm{C}, 5 \% \mathrm{CO}_{2}$ for $2 \mathrm{~h}$. Wells were then washed

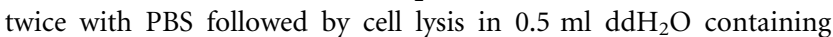
$0.1 \%$ Triton X-100 for $10 \mathrm{~min}$. at room temperature. Wells were washed one more time with PBS and samples were pooled with the Triton X-100 lysis fraction of recovered bacteria. Duplicate wells were used to determine the total number of bacteria per well. For this purpose, all medium and washes were pooled. Tenfold dilutions in PBS were plated on LB agar plates containing $10 \mu \mathrm{g}$ chloramphenicol $\mathrm{ml}^{-1}$. The plates were incubated at $37{ }^{\circ} \mathrm{C}$ overnight and the output c.f.u. were enumerated. Adhesion is expressed as the percentage of adherent bacteria relative to the total number of bacteria in a parallel infected well (total inoculum after $2 \mathrm{~h}$ ).

Adhesion assays for $Y$. pestis strains were performed similarly, except that bacteria were grown in the absence of IPTG and chloramphenicol and cells were plated on $\mathrm{HIB}$ agar at $28{ }^{\circ} \mathrm{C}$ for $48 \mathrm{~h}$ prior to quantification.

Autoaggregation assay. E. coli AAEC185 containing the empty vector pMMB207, pMMB207-yapC or pMMB207-psaABC were grown overnight in LB with $10 \mu \mathrm{g}$ chloramphenicol $\mathrm{ml}^{-1}$ and $100 \mu \mathrm{M}$ IPTG. Cells were pelleted and resuspended at an $\mathrm{OD}_{600}$ of 1.5 in $2 \mathrm{ml}$ DMEM in glass test tubes. Tubes were incubated in a $37{ }^{\circ} \mathrm{C}$ water bath and $\mathrm{OD}_{600}$ was read every $15 \mathrm{~min}, 30 \mathrm{~min}$ or $60 \mathrm{~min}$ as the assay progressed. As bacteria aggregated, they settled out of the DMEM solution, resulting in a decrease in $\mathrm{OD}_{600}$.

Biofilm formation assay. Crystal violet staining was used to detect cells attached to polystyrene as described by O'Toole et al. (1999). 
Briefly, overnight bacterial cultures were diluted $1: 100$ into LB plus $10 \mu \mathrm{g}$ chloramphenicol $\mathrm{ml}^{-1}$ and $100 \mu \mathrm{M}$ IPTG in flat-bottomed polystyrene culture plates (Costar Corning) and incubated $24 \mathrm{~h}$ at $37{ }^{\circ} \mathrm{C}$ or $28{ }^{\circ} \mathrm{C}$ without shaking. The optical density of the cultures was read in a microplate reader (Perkin Elmer Lambda Reader) at $595 \mathrm{~nm}$. Plates were washed twice with PBS, and $0.01 \%$ crystal violet was added and incubated for $15 \mathrm{~min}$ at room temperature. Wells were washed three times with distilled water, and stained bacteria were solubilized with $80 \%$ ethanol and $20 \%$ acetone mixture. Absorbance of the mixture was measured by the microplate reader at $595 \mathrm{~nm}$. Results were normalized for bacterial culture density. $Y$. pestis assays were performed similarly except that no IPTG or chloramphenicol was added and cells were grown in a defined medium, PMH2 (Gong et al., 2001; Staggs \& Perry, 1991).

RT-PCR. Expression of yapC under various in vitro growth conditions was assessed using reverse transcription (RT)-PCR. KIM5 or KIM5 $\triangle y a p C$ was grown under three different conditions in HIB: $28{ }^{\circ} \mathrm{C} \mathrm{pH} 7,37^{\circ} \mathrm{C} \mathrm{pH} 6$ and $37^{\circ} \mathrm{C} \mathrm{pH}$ 7. Bacterial cells were prepared for RNA extraction with Trizol according to the manufacturer's recommendations (Invitrogen). RNA samples were treated with DNase I for $10 \mathrm{~min}$ at $37{ }^{\circ} \mathrm{C}$ to degrade contaminating DNA followed by inactivation of DNase I with $2 \mathrm{mM}$ EDTA and heating to $65{ }^{\circ} \mathrm{C}$ for $10 \mathrm{~min}$. RNA was then precipitated with sodium acetate and ethanol and washed with $70 \%$ ethanol prior to performing the RT-PCRs. RNA samples of $500 \mathrm{ng}$ were used for reverse transcription, using random hexamer primers and Superscript II reverse transcriptase as described by the manufacturer (Invitrogen). PCR amplification was performed using the yapC or $16 \mathrm{~S}$ rRNA primer pairs listed in Supplementary Table S1 (available with the online version of this paper). Thirty cycles of amplification were performed using an annealing temperature of $47{ }^{\circ} \mathrm{C}$. Products were then run on a $2 \%$ agarose gel, stained with ethidium bromide and imaged for visualization of appropriately sized PCR products. Negative control samples were processed in parallel, but no reverse transcriptase was added. A positive control PCR reaction was carried out using KIM5 chromosomal DNA.

Detecting YapC surface expression. YapC was detected on the surface of $Y$. pestis using an anti-YapC antibody generated in the laboratory of Dr Virginia Miller (Department of Molecular Microbiology, Washington University School of Medicine). Y. pestis KIM5 or the KIM5 $\Delta y a p C$ mutant was grown overnight in HIB at $28{ }^{\circ} \mathrm{C} \mathrm{pH} 7$ (starting $\mathrm{pH}$ ). Overnight cultures were diluted $1: 50$ into HIB and grown under three conditions: $28^{\circ} \mathrm{C} \mathrm{pH} \mathrm{7,37}{ }^{\circ} \mathrm{C} \mathrm{pH} 7$ and $37{ }^{\circ} \mathrm{C} \mathrm{pH}$ 6. Cells were grown to mid-exponential phase $(4 \mathrm{~h})$ and then cells were pelleted, washed once with $1 \mathrm{ml}$ PBS and resuspended at an equivalent $\mathrm{OD}_{620}$ concentration $\left(\mathrm{OD}_{620} 0.424\right)$ in an Eppendorf tube. Cells were then fixed for $20 \mathrm{~min}$ at room temperature with $500 \mu \mathrm{l} 4 \%$ paraformaldehyde (with rolling), washed once with $1 \mathrm{ml}$ PBS and blocked for $3 \mathrm{~h}$ at room temperature with $1 \mathrm{ml} \mathrm{PBS}+1 \%$ BSA (with rolling). Cells were then pelleted and resuspended in $500 \mu \mathrm{l}$ PBS $+0.2 \%$ BSA $+0.05 \%$ Tween-20 + a 1:500 dilution of the rabbit anti-YapC antibody. Bacteria and antibody were co-incubated overnight at $4{ }^{\circ} \mathrm{C}$ with rolling. Cells were then pelleted and washed twice with $1 \mathrm{ml}$ PBS (with resuspension and pelleting), after which $500 \mu \mathrm{lBS}+0.2 \%$ BSA $+0.05 \%$ Tween- $20+1: 1000$ goat anti-rabbit alkaline phosphatase-conjugated secondary antibody (Zymed) was incubated with the bacteria for $45 \mathrm{~min}$ at room temperature. Cells were then washed three times with $1 \mathrm{ml}$ PBS and once with $1 \mathrm{ml}$ $100 \mathrm{mM}$ Tris $\mathrm{pH} 8.0$, and reactions for detection of antibody binding were performed in $500 \mu 100 \mathrm{mM}$ Tris $\mathrm{pH} 8.0+4 \mathrm{mg} \mathrm{ml}^{-1}$ of the alkaline phosphatase substrate PNPP (Fluka). Reactions were developed for between 19 and $27 \mathrm{~min}$ prior to spinning out the bacteria and transferring the supernatants to a 96-well plate for reading in an ELISA plate reader at $405 \mathrm{~nm}$. Results were normalized to YapC surface expression of KIM5 grown overnight in HIB at
$28{ }^{\circ} \mathrm{C} . A_{405}$ readings were corrected for the time of PNPP development. E. coli samples were processed identically, except that they were induced with $100 \mu \mathrm{M}$ IPTG during the $4 \mathrm{~h}$ growth in LB at $37^{\circ} \mathrm{C}$ and exposed to PNPP for $8 \mathrm{~min}$.

\section{RESULTS}

\section{YapC of $Y$. pestis mediates adhesion to cultured cells}

Adhesins can potentially enhance colonization of $Y$. pestis during infection or may play a role in Yop delivery to targeted host cells. To determine whether YapC can bind host cells, we analysed the ability of YapC to enhance attachment of the Fim ${ }^{-}$E. coli strain AAEC185 (Blomfield et al., 1991) to murine-derived macrophage-like cells (RAW264.7) or human-derived epithelial-like cells (HEp2). Adhesion of E. coli expressing YapC to RAW264.7 macrophages and HEp-2 cells was analysed by a c.f.u. assay (see Methods). For these studies, the known $Y$. pestis adhesin $\mathrm{pH} 6$ antigen (encoded by the $p s a A B C$ locus) served as a positive control for efficient cell binding. E. coli expressing YapC showed a twofold increase in adhesion to RAW264.7 cells ( $28 \%$, corresponding to $\sim 1$ bacterium per cell using our m.o.i. of $\sim 3$ ) when compared to E. coli carrying the empty expression vector pMMB207 (Fig. 1a). The positive control, pH 6 antigen, provided $59 \%$ adhesion ( 2 bacteria per cell) to RAW264.7 macrophages. On HEp-2 cells (where background binding by E. coli

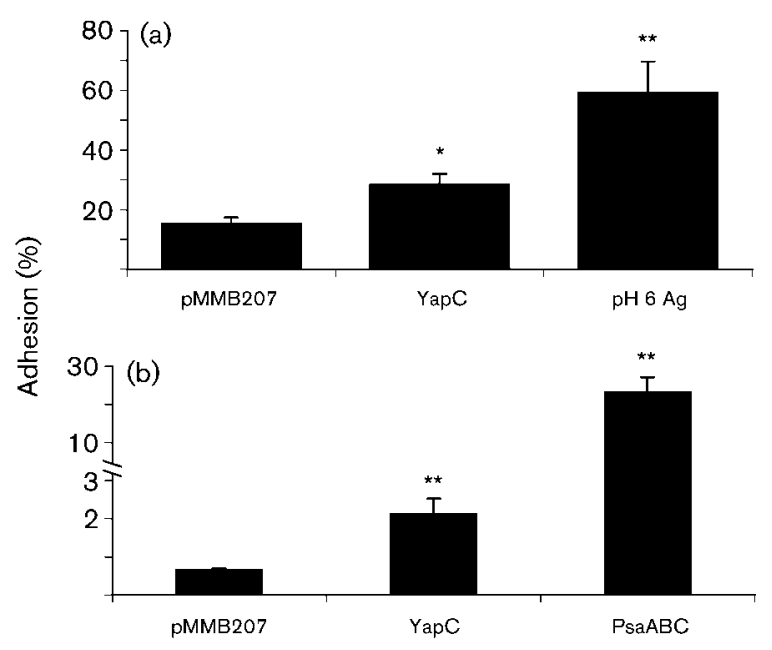

Fig. 1. Adhesion of E. coli AAEC185 expressing YapC to RAW264.7 macrophages (a) and HEp-2 cells (b). E. coli cells were grown overnight at $28{ }^{\circ} \mathrm{C}$ in LB containing $100 \mu \mathrm{M} \mathrm{IPTG}$ and tissue culture cells were infected at an m.o.i. of approximately 1-3 bacteria per cell for $2 \mathrm{~h}$. Adhesion was quantified as the number of cell-associated c.f.u. divided by total c.f.u. in the tissue culture well (\% bound out of total inoculum). Values are the means and standard deviations of three independent experiments with duplicate assays from each experiment. *, $P<0.001$, **, $P<0.00001$ as assessed by Student's $t$-test. 


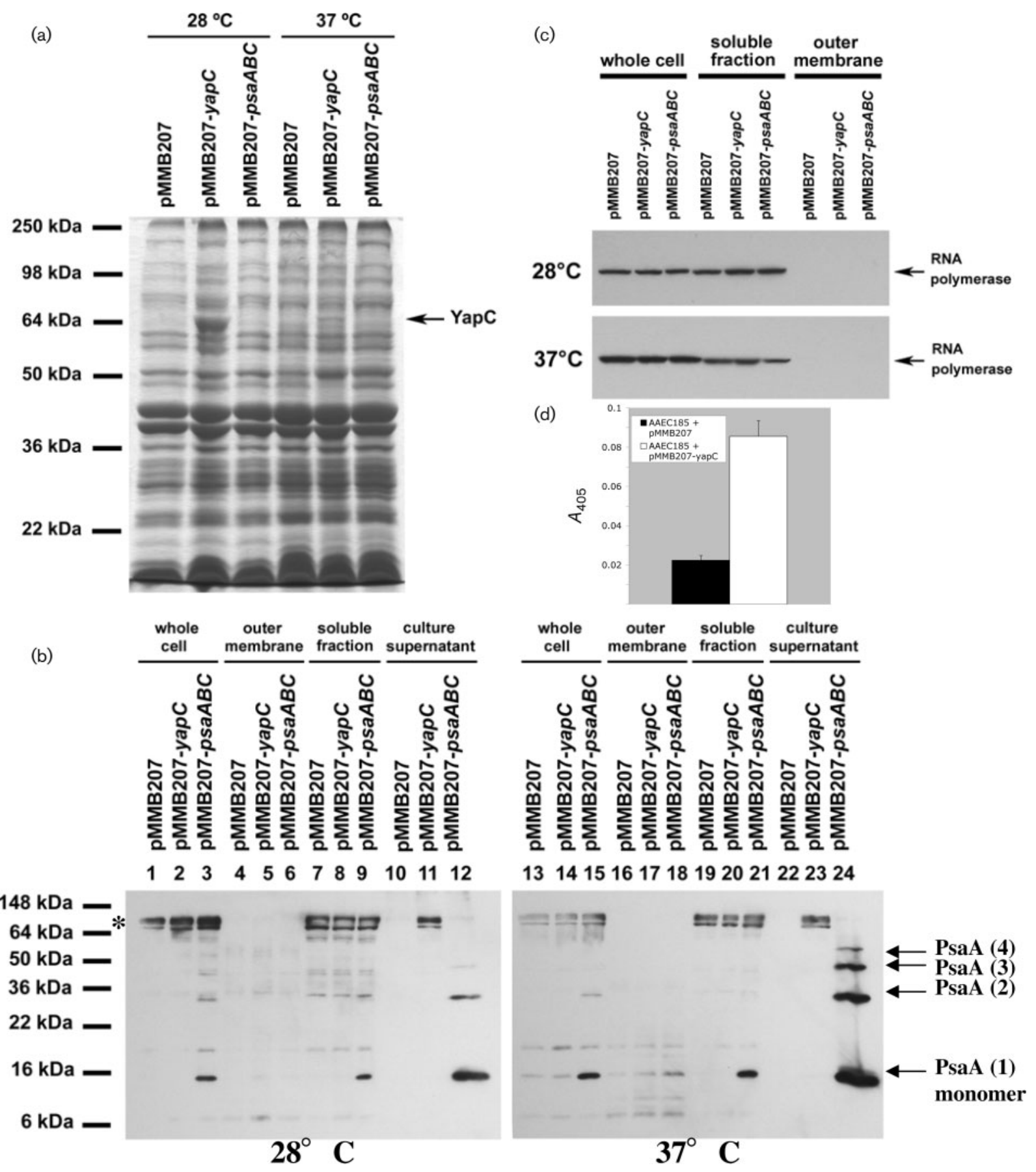

Fig. 2. Expression of $\mathrm{YapC}$ and $\mathrm{pH} 6$ antigen in the outer membranes of E. coli AAEC185. (a) Outer membranes were subjected to SDS-PAGE and stained with Coomassie blue. A predicted $65 \mathrm{kDa}$ band for YapC is indicated with an arrow. (b) Various cell fractions prepared from cells grown at $28^{\circ} \mathrm{C}$ or $37{ }^{\circ} \mathrm{C}$ were subjected to SDS-PAGE and probed with an antiPsaA antibody for Western blot analysis ( ${ }^{*}$ indicates an E. coli protein that is cross-reactive with anti-PsaA antibody). (c) Various cell fractions were subjected to SDS-PAGE and probed with an anti-RNA polymerase $\alpha$-subunit antibody for Western blot analysis. 'Soluble fraction' indicates cell components extracted by Triton X-100, including inner membranes and cytoplasm (Hantke, 1984). (d) E. coli cells harbouring empty vector (pMMB207) or vector carrying yapC were induced for $4 \mathrm{~h}$ with $100 \mu \mathrm{M}$ IPTG in triplicate and analysed for surface expression of YapC with an anti-YapC antibody. Shown is a representative experiment from one day. 
AAEC185 was lower), YapC showed a 3.3-fold increase (up to $2.1 \%$ adhesion) in cell adhesion compared to $E$. coli with plasmid pMMB207 (0.65\% adhesion, Fig. 1b). pH 6 antigen conferred upon E. coli AAEC185 23.9\% adhesion for HEp-2 cells, demonstrating its strong adhesive ability. Giemsa staining of adhesion assays verified these findings, as E. coli expressing either YapC or $\mathrm{pH} 6$ antigen showed higher numbers of bacteria bound per cell than E. coli carrying empty vector (data not shown).

We also assessed the effect of a $\Delta y a p C$ mutation on $Y$. pestis adhesion. A KIM5 $\Delta y a p C$ mutant had no defect in adhesion to either RAW264.7 macrophages or HEp-2 cells when pregrown at $28{ }^{\circ} \mathrm{C}$ or $37{ }^{\circ} \mathrm{C}$ (data not shown). Since the Cafl capsule of $Y$. pestis (expressed at $37{ }^{\circ} \mathrm{C}$ ) has been shown to interfere with the ability of some $Y$. pestis proteins to bind mammalian cells (Liu et al., 2006) and capsule production interferes with the activity of the E. coli TibA protein (Sherlock et al., 2005), we also constructed a $\Delta c a f 1 \Delta y a p C$ mutant of KIM5. The $\Delta c a f 1 \Delta y a p C$ mutant also had no cell-binding defect for RAW264.7 or HEp-2 cells (data not shown). The $\triangle$ yapC mutant also had no defect in delivery of cytotoxic Yop proteins (a process which requires adhesins; Rosqvist et al., 1990) as measured by pCD1-dependent cell rounding (data not shown). The lack of an effect on cell binding in the $\triangle y a p C$ mutant suggests that $Y$. pestis expresses multiple adhesins capable of host cell binding or that expression of YapC in vitro is low.

\section{Expression of YapC in the outer membrane}

To confirm the expression of YapC in the outer membrane of $E$. coli, we cultured strains carrying the pMMB207-yapC plasmid overnight at $28{ }^{\circ} \mathrm{C}$ or $37{ }^{\circ} \mathrm{C}$ in Luria-Bertani (LB) medium supplemented with $100 \mu \mathrm{M}$ IPTG to induce yapC expression and outer-membrane proteins were prepared according to the Triton X-100 extraction method of Hantke (1984). YapC was clearly visible as a predicted $65 \mathrm{kDa}$ band (consistent with signal peptide processing) present in E. coli outer membranes (Fig. 2a, lanes 2 and 5), and its identity was confirmed by mass spectrometry (data not shown). Although pH 6 antigen was expressed, as evidenced by its ability to mediate cell adhesion (Fig. 1), it was poorly detected in our outer membrane preparations, when stained with Coomassie blue (Fig. 2a, lanes 3 and 6; PsaA is a predicted $15 \mathrm{kDa}$ protein). Since fimbria-like structures are often shed or sheared from the surface of bacterial cells during processing (Hoschutzky et al., 1989), we looked at the culture supernatants after spinning overnight cultures of bacteria at 7000 r.p.m. in a laboratory microcentrifuge. Anti-PsaA (the structural subunit of $\mathrm{pH} 6$ antigen) Western blots performed on bacterial cell extracts or supernatants that were normalized to represent the amounts produced by similar numbers of bacteria demonstrated that the vast majority of PsaA filaments are sheared from AAEC185 during this initial bacterial pelleting step (Fig. 2b, lanes 12 and 24). PsaA was present in the culture supernatants of both $28{ }^{\circ} \mathrm{C}$ and $37{ }^{\circ} \mathrm{C}$ preparations of AAEC185/pMMMB207-psaABC (Fig. 2b). We were even able to visualize various polymerized forms (presumably incompletely denatured in our SDS-PAGE system) of pH 6 antigen (monomer to tetramer; Fig. 2b, lanes 12 and 24). It appears that only a small proportion of PsaA remains membrane-associated during our outer membrane preparation protocol, yet clearly PsaA-expressing E. coli cells have $\mathrm{pH} 6$ antigen-mediated adhesive activity (leading to $24-59 \%$ adhesion, depending on the cell line). Comparisons of RNA polymerase contamination from the cytosolic/inner-membrane Triton X-100-soluble fraction demonstrated minimal contamination when whole-cell lysates were compared with outer-membrane preparations (Fig. 2c).

There is an E. coli protein (denoted by an asterisk in Fig. 2b) that is cross-reactive with anti-PsaA antisera. Based on its fractionation, this protein is from either the cytoplasm or the inner membrane (Triton X-100-soluble fraction, Fig. 2b). The fact that we see some of this cross-reactive protein in supernatants from YapC-expressing E. coli suggests that YapC expression may be somewhat toxic to E. coli, causing some cells to lyse and release intracellular contents into the supernatant.

YapC surface expression in E. coli was also demonstrated using a recently generated anti-YapC antibody. AAEC185 carrying pMMB207 (empty vector) or pMMB207-yapC was grown for $4 \mathrm{~h}$ in LB with $100 \mu \mathrm{M}$ IPTG induction. Cells were washed, fixed and processed for anti-YapC surface labelling as described in Methods. Expression of YapC in E. coli gave a more than fourfold increase in antiYapC antibody recognition (Fig. 2d).

\section{YapC mediates $E$. coli autoaggregation in tissue culture media}

Another phenotype associated with TibA (the YapC homologue) in ETEC is autoaggregation (Sherlock et al., 2005). Autoaggregation in tissue culture medium is also associated with virulence in Yersinia species (Laird \& Cavanaugh, 1980). Therefore, we investigated the ability of YapC to direct E. coli autoaggregation in DMEM tissue culture medium at $37{ }^{\circ} \mathrm{C}$. These studies were performed in the Fim ${ }^{-}$E. coli derivative AAEC185 since the E. coli Fim system also mediates autoaggregation in tissue culture media (S. Felek \& E. S. Krukonis, unpublished observations). Bacteria were induced for YapC or $\mathrm{pH} 6$ antigen expression overnight at $28{ }^{\circ} \mathrm{C}$ with $100 \mu \mathrm{M}$ IPTG, pelleted, resuspended in DMEM at $37{ }^{\circ} \mathrm{C}$ at an $\mathrm{OD}_{600}$ of 1.5 and monitored for aggregation by $\mathrm{OD}_{600}$ measurements over time. Expression of YapC led to aggregation of E. coli AAEC185 within 15-30 min and a 50\% reduction in $\mathrm{OD}_{600}$ occurred by approximately $45 \mathrm{~min}$ after resuspension in DMEM (Fig. 3). AAEC185 expressing the empty plasmid pMMB207 or $\mathrm{pH} 6$ antigen showed no autoaggregation for up to $6 \mathrm{~h}(360 \mathrm{~min})$ post-transfer to DMEM (Fig. 3). 


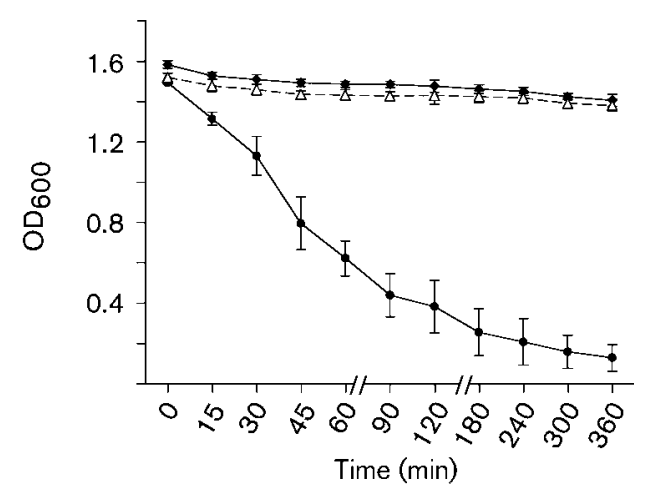

Fig. 3. Autoaggregation of $E$. coli AAEC185 expressing YapC or $\mathrm{pH} 6$ antigen in DMEM at $37^{\circ} \mathrm{C}$. Cells carrying empty vector (pMMB207) were used as control. Cells were monitored in a test tube for clearing over time. Results are the mean $\pm S D$ of three experiments on different days. pMMB207; ○, YapC; $\triangle$, PsaABC.

The loss of optical density that we see in DMEM is not due to cell death since we know from our adhesion assays that YapC-expressing E. coli maintain high c.f.u. counts for up to $2 \mathrm{~h}$ in DMEM (Fig. 1 and Methods).

A recent report by Yen et al. (2007) also demonstrated that expression of YapC in E. coli leads to autoaggregation, although in this case bacterial aggregation was tested in LB bacterial culture medium, not tissue culture medium.

$Y$. pestis also undergoes autoaggregation when grown at $28{ }^{\circ} \mathrm{C}$. This phenotype is blocked by expression of the Caf1 protein capsule at $37^{\circ} \mathrm{C}$ (S. Felek \& E. S. Krukonis, unpublished observations). We tested our KIM5 $\Delta y a p C$ mutant for clumping in several media, including HIB, LB, PBS and DMEM. There was no difference in autoaggregation in any media between KIM5 and KIM5 $\Delta y a p C$ (data not shown). Subsequent investigations have revealed that a major determinant of KIM5 autoaggregation is a metabolic gene that is likely involved in LPS modifications (S. Felek \& E. S. Krukonis, unpublished observations). Deletion of this locus results in a dramatic decrease in autoaggregation of KIM5.

\section{YapC promotes biofilm-like deposits in E. coli}

Since autoaggregation of bacteria is a critical step in biofilm formation, we assessed the ability of YapC to mediate formation of biofilm-like deposits in $E$. coli. Furthermore, the ETEC YapC homologue, TibA, has been shown to mediate biofilm formation in ETEC.

Biofilm assays were performed by incubating E. coli AAEC185 containing vector pMMB207 or pMMB207yapC in LB medium in sterile 96-well polystyrene plates. YapC expression led to a 5.3-fold increase in AAEC185 biofilm formation (as measured by crystal violet staining) when the bacteria were grown at $37{ }^{\circ} \mathrm{C}$ and an 8 -fold increase when grown at $28{ }^{\circ} \mathrm{C}$ (Fig. 4). Thus, YapC has the potential to play a role in $Y$. pestis biofilm formation in both the human host and the flea vector.

Since YapC affected the formation of biofilm-like structures in E. coli, we investigated the role of this locus in $Y$. pestis biofilm formation. KIM5 or an isogenic $\Delta y a p C$ mutant were grown overnight in PMH2 medium (Gong et al., 2001; Staggs \& Perry, 1991) at $28{ }^{\circ} \mathrm{C}$ or $37{ }^{\circ} \mathrm{C}$ in sterile 96-well polystyrene plates. We did not detect a defect in biofilm-like deposits in the yapC mutant at either temperature (data not shown).

Given that at $37^{\circ} \mathrm{C}$ YapC may be masked by the F1 capsule of KIM5, we also tested an isogenic caf1 mutant for biofilm formation in the presence or absence of YapC. Again, we saw no difference in biofilm-like deposits in a KIM5 $\Delta$ caf1 mutant compared to the $\Delta c a f 1 \Delta y a p C$ mutant (data not shown). It should be noted that KIM5 lacks the hms locus responsible for biofilm-dependent flea blockage by $Y$. pestis (Hinnebusch et al., 1996). Thus, biofilm formation in the KIM5 assays is via a different mechanism and is considered $h m s$-independent.

\section{Expression profile of yapC under various growth conditions}

Using RT-PCR, Yen et al. (2007) found that yapC of $Y$. pestis $\mathrm{KIM} 10+$ is expressed in $\mathrm{HIB}$ at $28{ }^{\circ} \mathrm{C}$. Since the three activities of YapC - cell adhesion, autoaggregation and biofilm formation - may be important in either the human host or the flea vector, we assessed yapC expression in $Y$. pestis under various in vitro growth conditions.

Parental KIM5 cells or a $\triangle y a p C$ mutant were grown overnight at $28{ }^{\circ} \mathrm{C} \mathrm{pH} \mathrm{7,} \mathrm{diluted} \mathrm{to} \mathrm{OD}_{620} 0.2$ and grown for $4 \mathrm{~h}$ at $37^{\circ} \mathrm{C} \mathrm{pH} \mathrm{7,} \mathrm{at} 37^{\circ} \mathrm{C} \mathrm{pH} 6$ (conditions which induce pH 6 antigen expression) or at $28{ }^{\circ} \mathrm{C} \mathrm{pH} \mathrm{7.} \mathrm{RNA}$ was isolated using a Trizol extraction protocol and

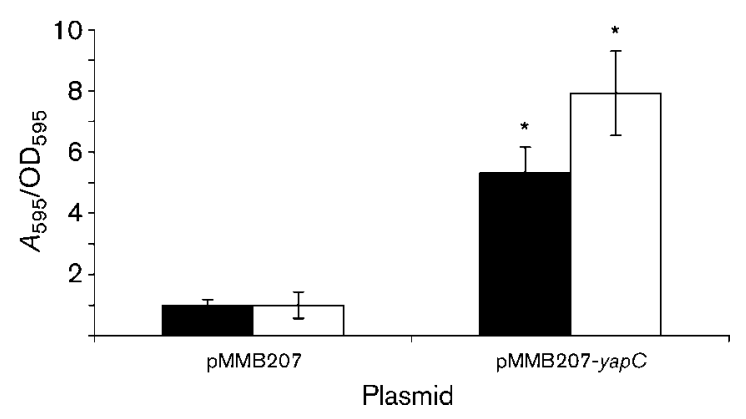

Fig. 4. Formation of biofilm-like deposits by $E$. coli at $37{ }^{\circ} \mathrm{C}$ (black bars) and $28^{\circ} \mathrm{C}$ (white bars). Results are the mean \pm SD crystal violet absorbance $\left(A_{595}\right)$ divided by bacterial culture density $\left(O D_{595}\right.$, prior to crystal violet staining) of three independent experiments with at least duplicate assays from each experiment. Results are normalized to set the AAEC185/pMMB207 $28^{\circ} \mathrm{C}$ control at 1.0. ${ }^{*}, P<0.00001$ as assessed by Student's $t$-test. 
RT-PCR was performed as described in Methods. Primers within the yapC-coding region led to amplification of a $113 \mathrm{bp}$ product under all conditions and this product was absent in the $\triangle y a p C$ deletion mutant (Fig. 5a). This amplification product was also dependent upon reverse transcriptase (only present in ' + ' lanes in Fig. 5). Thus, it was not due to DNA contamination. We also amplified the $16 \mathrm{~S}$ rRNA transcript by RT-PCR and showed it was amplified equally well in both KIM5 and the $\Delta y a p C$ derivative (resulting in a $125 \mathrm{bp}$ band, Fig. 5b), indicating that the $\Delta y a p C$ samples were competent for productive RTPCR. Although these results indicate that yapC is expressed in $Y$. pestis under all three of the growth conditions we routinely use in the laboratory, such end-point (30 cycle) PCR reactions are non-quantitative. By comparing the
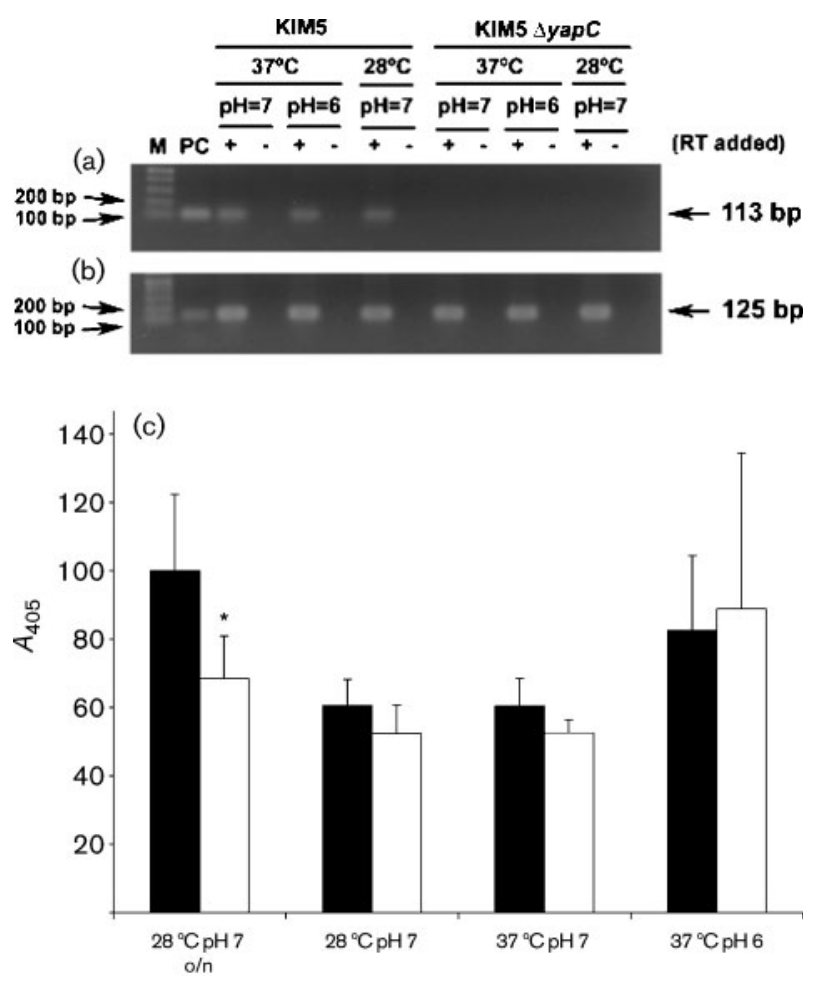

Fig. 5. Expression of yapC under various in vitro growth conditions. KIM5 and KIM5 $\triangle y a p C$ were grown from an $\mathrm{OD}_{620}$ of 0.2 to an $O_{620}$ of $0.7-0.9$. Cells were pelleted and RNA extracted. RT-PCR was performed using two sets of primers. (a) Amplification of a $113 \mathrm{bp}$ yapC-encoded transcript. (b) Amplification of a 125 bp $16 \mathrm{~S}$ rRNA transcript. Lane PC refers to a positive control sample using chromosomal DNA as a PCR template. (c) Surface expression of YapC protein was assessed for overnight $(\mathrm{o} / \mathrm{n})$ cultures of KIM5 (black bars) and KIM $\Delta y a p C$ (white bars) grown in HIB at $28{ }^{\circ} \mathrm{C} \mathrm{pH} \mathrm{7,} \mathrm{and} \mathrm{for} \mathrm{cultures} \mathrm{diluted}$ $1: 50$ from the overnight culture and grown for $4 \mathrm{~h}$ at $28^{\circ} \mathrm{pH} \mathrm{7,}$ $37^{\circ} \mathrm{pH} 7$ and $37^{\circ} \mathrm{pH} 6$. YapC protein on the surface of KIM5 was detected with an anti-YapC antibody. Shown is a representative experiment on cultures grown in triplicate. ${ }^{*}, P=0.1$ between KIM5 and KIM5 $\triangle y a p C$ for the $28{ }^{\circ} \mathrm{C}$ overnight cultures (as assessed by Student's $t$-test).
yapC and $16 \mathrm{~S}$ rRNA reaction products, it appears that yapC is expressed less well (Fig. 5a, b). Upon further investigation, by examining PCR products after 50 rounds of amplification, using several different dilutions of the template cDNA, it was determined that yapC expression levels are about 1000-fold lower than that of 16S rRNA (data not shown).

In addition to RT-PCR, we determined the surface expression of YapC protein on KIM5 under various growth conditions. KIM5 or the $\triangle y a p C$ mutant were grown overnight at $28{ }^{\circ} \mathrm{C}$ (starting $\mathrm{pH}$ 7) and then diluted 1:50 for $4 \mathrm{~h}$ growth under various conditions. YapC expression on the surface of KIM5 was assessed using an anti-YapC antibody (Methods). The only condition where we observed an increase in YapC surface expression compared to the $\Delta y a p C$ isogenic control was when KIM5 was grown overnight to stationary phase at $28{ }^{\circ} \mathrm{C}$ (Fig. 5 c; $P=0.1$ ). Thus, YapC appears to be poorly expressed in vitro (possibly induced in stationary phase), but may be expressed during infection. The fact that YapC is poorly expressed in vitro likely contributes to our inability to observe a strong yapC mutant phenotype in our various assays.

\section{DISCUSSION}

Adhesins are important virulence factors that facilitate successful colonization and can affect the tissue tropism(s) of a particular micro-organism (Niemann et al., 2004; Ofek et al., 2003). Many bacterial pathogens maintain multiple adhesins to enable binding to various cell types. In some bacteria, more than ten adhesins have been described (Ofek et al., 2003).

TibA is an ETEC glycoprotein that has been shown to mediate glycosylation-dependent binding to and invasion of several cell types (Elsinghorst \& Kopecko, 1992; Elsinghorst \& Weitz, 1994; Lindenthal \& Elsinghorst, 2001). In this study, we found that YapC, a Y. pestis TibA homologue, can function as an adhesin. It promotes adhesion of E. coli AAEC185 to both RAW264.7 macrophages and HEp-2 cells (Fig. 1). We also confirmed the strong adhesive ability of the known $Y$. pestis adhesin, pH 6 antigen (Fig. 1; Yang et al., 1996). A recent study by Yen et al. (2007) found that YapC expressed in E. coli was unable to mediate haemagglutination of sheep red blood cells. In those experiments, the starting dilution of bacterial cells was $1: 10$. We could detect weak haemagglutination activity in E. coli expressing YapC to a bacterial dilution of $1: 4$ (data not shown). It is also possible that RAW264.7 macrophages and HEp-2 cells express a YapC receptor that is poorly expressed on erythrocytes. It should be noted that in our HEp-2 and RAW264.7 adhesion studies, some component of the increased adhesion might be due to the autoaggregative activity of YapC in E. coli (Fig. 3). YapC expressed in E. coli also mediated a two- to fourfold increase in adhesion to two other human-derived cell lines: 
THP-1 monocyte-like cells and A549 cells derived from lung epithelium (data not shown).

Another important bacterial process dependent on surface structures is biofilm formation. Biofilms are often important for bacterial virulence, facilitating colonization and protecting bacteria from host immune defence and antimicrobial treatments (Fux et al., 2005; Stewart \& William Costerton, 2001). Attachment of bacteria to a surface is the first step in biofilm formation, followed by replication to form microcolonies to produce a mature biofilm (Jefferson, 2004). Biofilm formation blocks the proventriculus of the flea and is important for transmission of bubonic plague (Darby et al., 2002; Jarrett et al., 2004). The HmsT and HmsP proteins have been shown previously to control biofilm production in $Y$. pestis at $28{ }^{\circ} \mathrm{C}$; these proteins are thought to be critical only for the flea (ambient temperature) stage of the $Y$. pestis life cycle since HmsT is degraded at $37{ }^{\circ} \mathrm{C}$ (Kirillina et al., 2004). We found that YapC mediates biofilm formation at both $37{ }^{\circ} \mathrm{C}$ and $28{ }^{\circ} \mathrm{C}$ in E. coli (Fig. 4). Thus, YapC may mediate biofilm formation during infection of mammalian hosts and/or the flea vector. YapC-mediated autoaggregation of bacterial cells (Fig. 3) may also contribute to biofilm formation. The ETEC YapC homologue, TibA, also induces biofilm formation in E. coli (Sherlock et al., 2005). When tested in $Y$. pestis, a $\Delta y a p C$ mutant of KIM5 had no defect in biofilm formation (data not shown). Autoaggregation in DMEM, perhaps an early step in biofilm formation, was also not affected in the $\Delta y a p C$ mutant (data not shown). Thus, while we have shown that YapC possesses certain activities, there are apparently redundant proteins with similar activities in $Y$. pestis. In the case of biofilm formation, we know that expression of several annotated $Y$. pestis chaperone/usher systems also results in biofilm formation (Felek et al., 2007) and we have recently identified a locus in $Y$. pestis that controls autoaggregation (S. Felek \& E. S. Krukonis, unpublished). In addition, the expression of YapC in vitro appears to be fairly low (Fig. 5). The fact that YapC is poorly expressed in vitro likely contributes to our inability to observe a yapC mutant phenotype in our various assays.

It has been demonstrated that adhesins are required for Yop delivery in Y. pestis (Rosqvist et al., 1990). Yop delivery leads to cytotoxicity in eukaryotic cells. Our results and previous studies by others demonstrate that $Y$. pestis has at least three adhesins: YapC (Fig. 1), pH 6 antigen (Fig. 1 and Yang et al., 1996) and plasminogen activator (Kienle et al., 1992; Lahteenmaki et al., 1998). We tested various $Y$. pestis mutant strains for cytotoxicity in cultured cells. A $\Delta y a p C$ or $\Delta p s a A$ mutant of $Y$. pestis KIM5 showed wildtype levels of cytotoxicity for RAW264.7 macrophages and HEp-2 cells (data not shown), as assessed by cell rounding. As expected, a KIM5 $\mathrm{pCD1}^{-}$(Yop-negative control) strain did not cause cytotoxicity (data not shown). In addition, a triple mutant KIM8 (plasminogen activator negative, pla) pla $\Delta y a p C \Delta p s a A$ strain was also able to deliver Yop proteins to eukaryotic cells with wild-type efficiency when pregrown at $28{ }^{\circ} \mathrm{C}$ pH 7 (data not shown). It should be noted that a $\Delta p s a A$ mutant shows a $1-2 \mathrm{~h}$ delay in Yop-mediated cytotoxicity when pregrown at $37^{\circ} \mathrm{C} \mathrm{pH} 6$ (data not shown). This $\mathrm{pH} 6$ antigen-dependent reduction in Yop delivery confirms the ability of $\mathrm{pH} 6$ antigen to facilitate delivery of T3SS proteins, as was shown previously in a non-adherent mutant of Pseudomonas aeruginosa, where expression of $\mathrm{pH} 6$ antigen established sufficient contact to allow type III secretion of the toxin ExoS (Sundin et al., 2002).

The results discussed above suggest that there are redundant adhesins in $Y$. pestis for cell binding and Yop delivery. These could include the recently described adhesive autotransporters YapN and YapK (Yen et al., 2007), or the chaperone/usher-dependent surface structure encoded by $Y$. pestis KIM locus y0561 (Felek et al., 2007). Alternatively, an uncharacterized adhesin may be specifically required for Yop delivery. It is important to note that the observation of redundant adhesins in vitro does not necessarily mean that the same adhesins are redundant in vivo. Environmental signalling and various forms of regulation may result in the expression of specific adhesins during different stages of $Y$. pestis infection. It may also be the case that Yop delivery to macrophages and neutrophils may be less dependent on a specific adhesin in addition to the YopB/D translocation complex, due to the phagocytic nature of these cells (Boyd et al., 2000). In the closely related pathogen $Y$. pseudotuberculosis, at least two adhesins, invasin and YadA, have been shown to be able to mediate Yop delivery (Rosqvist et al., 1990, 1994). This ability to deliver Yop proteins has also been shown to be dependent on adhesin length, with a minimum length required to establish proper contact for type III secretion (Mota et al., 2005). However, neither invasin nor YadA is functional in $Y$. pestis, due to IS element insertion or frame shift mutation, respectively (Deng et al., 2002; Parkhill et al., 2001).

In summary, we have demonstrated that YapC, an annotated autotransporter of $Y$. pestis, can mediate cell adhesion to HEp-2 (human) cells and RAW264.7 (mouse) macrophages, can lead to autoaggregation and can facilitate biofilm formation. Each of these activities can play an important role in the efficiency of establishing an infection or overcoming the host innate immune response. The role of TibA in ETEC pathogenesis is not defined, but the various activities of TibA and its $Y$. pestis homologue, YapC, suggest that these molecules may play important roles in pathogenesis. While other factors of $Y$. pestis may also possess some of these activities, we hypothesize that YapC may be an important player in the infection process.

\section{ACKNOWLEDGEMENTS}

This work was supported by grants from the University of Michigan School of Medicine Biomedical Research Core (BMRC) to E. S. K., the University of Michigan Office of the Vice President of Research (OVPR) to E. S. K. and grant NIAID R21 AI064313 to Dr Virginia 
Miller (for generation of anti-YapC antibodies). Protein identification (of YapC) by mass spectrometry was performed at the University of Michigan Proteome Consortium. We would like to thank Dr Greg Plano for providing strains KIM5-3001 and KIM8-3002. We would also like to thank Drs Plano and Don Court for providing advice on use of the $\lambda$-RED recombination system in $Y$. pestis. We thank Dr Susan Straley for providing anti-PsaA antibody. We thank Dr Virginia Miller for providing the anti-YapC antibody. Many thanks go to Dr James Bliska for helpful discussions throughout this work. Finally, we thank Drs Victor DiRita, Michele Swanson and J. Chris Fenno for critical reading of the manuscript.

\section{REFERENCES}

Achtman, M., Zurth, K., Morelli, G., Torrea, G., Guiyoule, A. \& Carniel, E. (1999). Yersinia pestis, the cause of plague, is a recently emerged clone of Yersinia pseudotuberculosis. Proc Natl Acad Sci U S A 96, 14043-14048.

Beesley, E. D., Brubaker, R. R., Janssen, W. A. \& Surgalla, M. J. (1967). Pesticins. III. Expression of coagulase and mechanism of fibrinolysis. J Bacteriol 94, 19-26.

Ben-Efraim, S., Aronson, M. \& Bichowsky-Slomnicki, L. (1961). New antigenic component of Pasteurella pestis formed under specified conditions of $\mathrm{pH}$ and temperature. J Bacteriol 81, 704-714.

Bichowsky-Slomnicki, L. \& Ben-Efraim, S. (1963). Biological activities in extracts of Pasteurella pestis and their relation to the "pH 6 antigen". J Bacteriol 86, 101-111.

Blomfield, I. C., McClain, M. S. \& Eisenstein, B. I. (1991). Type 1 fimbriae mutants of Escherichia coli K12: characterization of recognized afimbriate strains and construction of new fim deletion mutants. Mol Microbiol 5, 1439-1445.

Boyd, A. P., Grosdent, N., Totemeyer, S., Geuijen, C., Bleves, S., Iriarte, M., Lambermont, I., Octave, J.-N. \& Cornelis, G. R. (2000). Yersinia enterocolitica can deliver Yop proteins into a wide range of cell types: development of a delivery system for heterologous proteins. Eur J Cell Biol 79, 659-671.

Brubaker, R. R., Beesley, E. D. \& Surgalla, M. J. (1965). Pasteurella pestis: role of pesticin I and iron in experimental plague. Science 149, 422-424.

Cantor, N. (2001). In the Wake of the Plague. New York: Perennial.

Cornelis, G. R., Boland, A., Boyd, A. P., Geuijen, C., Iriarte, M., Neyt, C., Sory, M.-P. \& Stainier, I. (1998). The virulence plasmid of Yersinia, an antihost genome. Microbiol Mol Biol Rev 62, 1315-1352.

Cowan, C., Jones, H., Kaya, Y., Perry, R. \& Straley, S. (2000). Invasion of epithelial cells by Yersinia pestis: evidence for a Y. pestis-specific invasin. Infect Immun 68, 4523-4530.

Darby, C., Hsu, J. W., Ghori, N. \& Falkow, S. (2002). Caenorhabditis elegans: plague bacteria biofilm blocks food intake. Nature 417, 243-244.

Datsenko, K. A. \& Wanner, B. L. (2000). One-step inactivation of chromosomal genes in Escherichia coli K-12 using PCR products. Proc Natl Acad Sci U S A 97, 6640-6645.

Dautin, N., Barnard, T. J., Anderson, D. E. \& Bernstein, H. D. (2007). Cleavage of a bacterial autotransporter by an evolutionarily convergent autocatalytic mechanism. EMBO J 26, 1942-1952.

Deng, W., Burland, V., Plunkett, G., III, Boutin, A., Mayhew, G. F., Liss, P., Perna, N. T., Rose, D. J., Mau, B. \& other authors (2002). Genome sequence of Yersinia pestis KIM. J Bacteriol 184, 4601-4611.

Egile, C., d'Hauteville, H., Parsot, C. \& Sansonetti, P. J. (1997). SopA, the outer membrane protease responsible for polar localization of IcsA in Shigella flexneri. Mol Microbiol 23, 1063-1073.
Elsinghorst, E. A. \& Kopecko, D. J. (1992). Molecular cloning of epithelial cell invasion determinants from enterotoxigenic Escherichia coli. Infect Immun 60, 2409-2417.

Elsinghorst, E. A. \& Weitz, J. A. (1994). Epithelial cell invasion and adherence directed by the enterotoxigenic Escherichia coli tib locus is associated with a 104-kilodalton outer membrane protein. Infect Immun 62, 3463-3471.

Felek, S., Runco, L., Thanassi, D. G. \& Krukonis, E. S. (2007). Characterization of six novel chaperone/usher systems in Yersinia pestis. In 9th International Symposium on Yersinia, pp. 97-105. Lexington, KY, USA: Springer.

Fux, C. A., Costerton, J. W., Stewart, P. S. \& Stoodley, P. (2005). Survival strategies of infectious biofilms. Trends Microbiol 13, 34-40. Gong, S., Bearden, S. W., Geoffroy, V. A., Fetherston, J. D. \& Perry, R. D. (2001). Characterization of the Yersinia pestis Yfu ABC inorganic iron transport system. Infect Immun 69, 2829-2837.

Hantke, K. (1984). Cloning of the repressor protein gene of ironregulated systems in Escherichia coli K12. Mol Gen Genet 197, 337-341.

Henderson, I. R., Navarro-Garcia, F., Desvaux, M., Fernandez, R. C. \& Ala'Aldeen, D. (2004). Type V protein secretion pathway: the autotransporter story. Microbiol Mol Biol Rev 68, 692-744.

Hendrixson, D. R., de la Morena, M. L., Stathopoulos, C. \& St Geme, J. W., III (1997). Structural determinants of processing and secretion of the Haemophilus influenzae Hap protein. Mol Microbiol 26, 505-518.

Hinnebusch, B. J., Perry, R. D. \& Schwan, T. G. (1996). Role of the Yersinia pestis hemin storage $(\mathrm{hms})$ locus in the transmission of plague by fleas. Science 273, 367-370.

Hoschutzky, H., Lottspeich, F. \& Jann, K. (1989). Isolation and characterization of the $\alpha$-galactosyl-1,4- $\beta$-galactosyl-specific adhesin (P adhesin) from fimbriated Escherichia coli. Infect Immun 57, 76-81.

Isberg, R. R., Voorhis, D. L. \& Falkow, S. (1987). Identification of invasin: a protein that allows enteric bacteria to penetrate cultured mammalian cells. Cell 50, 769-778.

Jarrett, C. O., Deak, E., Isherwood, K. E., Oyston, P. C., Fischer, E. R., Whitney, A. R., Kobayashi, S. D., DeLeo, F. R. \& Hinnebusch, B. J. (2004). Transmission of Yersinia pestis from an infectious biofilm in the flea vector. J Infect Dis 190, 783-792.

Jefferson, K. K. (2004). What drives bacteria to produce a biofilm? FEMS Microbiol Lett 236, 163-173.

Kienle, Z., Emody, L., Svanborg, C. \& O'Toole, P. (1992). Adhesive properties conferred by the plasminogen activator of Yersinia pestis. J Gen Microbiol 138, 1679-1687.

Kirillina, O., Fetherston, J. D., Bobrov, A. G., Abney, J. \& Perry, R. D. (2004). HmsP, a putative phosphodiesterase, and HmsT, a putative diguanylate cyclase, control Hms-dependent biofilm formation in Yersinia pestis. Mol Microbiol 54, 75-88.

Lahteenmaki, K., Virkola, R., Saren, A., Emody, L. \& Korhonen, T. K. (1998). Expression of plasminogen activator Pla of Yersinia pestis enhances bacterial attachment to the mammalian extracellular matrix. Infect Immun 66, 5755-5762.

Lahteenmaki, K., Kukkonen, M. \& Korhonen, T. K. (2001). The Pla surface protease/adhesin of Yersinia pestis mediates bacterial invasion into human endothelial cells. FEBS Lett 504, 69-72.

Laird, W. J. \& Cavanaugh, D. C. (1980). Correlation of autoagglutination and virulence of yersiniae. J Clin Microbiol 11, 430-432.

Lindenthal, C. \& Elsinghorst, E. A. (2001). Enterotoxigenic Escherichia coli TibA glycoprotein adheres to human intestine epithelial cells. Infect Immun 69, 52-57.

Lindler, L. E. \& Tall, B. D. (1993). Yersinia pestis $\mathrm{pH} 6$ antigen forms fimbriae and is induced by intracellular association with macrophages. Mol Microbiol 8, 311-324. 
Lindler, L. E., Klempner, M. S. \& Straley, S. C. (1990). Yersinia pestis $\mathrm{pH} 6$ antigen: genetic, biochemical, and virulence characterization of a protein involved in the pathogenesis of bubonic plague. Infect Immun 58, 2569-2577.

Liu, F., Chen, H., Galvan, E. M., Lasaro, M. A. \& Schifferli, D. M. (2006). Effects of Psa and F1 on the adhesive and invasive interactions of Yersinia pestis with human respiratory tract epithelial cells. Infect Immun 74, 5636-5644.

Morales, V. M., Backman, A. \& Bagdasarian, M. (1991). A series of wide-host-range low-copy-number vectors that allow direct screening for recombinants. Gene 97, 39-47.

Mota, L. J., Journet, L., Sorg, I., Agrain, C. \& Cornelis, G. R. (2005). Bacterial injectisomes: needle length does matter. Science 307, 1278.

Niemann, H. H., Schubert, W.-D. \& Heinz, D. W. (2004). Adhesins and invasins of pathogenic bacteria: a structural view. Microbes Infect 6, 101-112.

O'Toole, G. A., Pratt, L. A., Watnick, P. I., Newman, D. K., Weaver, V. B. \& Kolter, R. (1999). Genetic approaches to study of biofilms. Methods Enzymol 310, 91-109.

Ofek, I., Hasty, D. L. \& Doyle, R. J. (2003). Bacterial Adhesion to Animal Cells and Tissues. Washington, DC: American Society for Microbiology.

Parkhill, J., Wren, B. W., Thomson, N. R., Titball, R. W., Holden, M. T., Prentice, M. B., Sebaihia, M., James, K. D., Churcher, C. \& other authors (2001). Genome sequence of Yersinia pestis, the causative agent of plague. Nature 413, 523-527.

Perry, R. D. \& Fetherston, J. D. (1997). Yersinia pestis - etiologic agent of plague. Clin Microbiol Rev 10, 35-66.

Rosqvist, R., Forsberg, A., Rimpilainen, M., Bergman, T. \& Wolf-Watz, H. (1990). The cytotoxic protein YopE of Yersinia obstructs the primary host defence. Mol Microbiol 4, 657-667.

Rosqvist, R., Magnusson, K. \& Wolf-Watz, H. (1994). Target cell contact triggers expression and polarized transfer of Yersinia YopE cytotoxin into mammalian cells. EMBO J 13, 964-972.

Shere, K. D., Sallustio, S., Manessis, A., D’Aversa, T. G. \& Goldberg, M. B. (1997). Disruption of IcsP, the major Shigella protease that cleaves IcsA, accelerates actin-based motility. Mol Microbiol 25, 451-462.
Sherlock, O., Vejborg, R. M. \& Klemm, P. (2005). The TibA adhesin/ invasin from enterotoxigenic Escherichia coli is self recognizing and induces bacterial aggregation and biofilm formation. Infect Immun 73, 1954-1963.

Sodeinde, O. A., Subrahmanyam, Y. V., Stark, K., Quan, T., Bao, Y. \& Goguen, J. D. (1992). A surface protease and the invasive character of plague. Science 258, 1004-1007.

Staggs, T. M. \& Perry, R. D. (1991). Identification and cloning of a fur regulatory gene in Yersinia pestis. J Bacteriol 173, 417-425.

Stewart, P. S. \& William Costerton, J. (2001). Antibiotic resistance of bacteria in biofilms. Lancet 358, 135-138.

Sundin, C., Wolfgang, M. C., Lory, S., Forsberg, A. \& Frithz-Lindsten, E. (2002). Type IV pili are not specifically required for contact dependent translocation of exoenzymes by Pseudomonas aeruginosa. Microb Pathog 33, 265-277.

Tamm, A., Tarkkanen, A.-M., Korhonen, T. K., Kuusela, P., Toivanen, P. \& Skurnik, M. (1993). Hydrophobic domains affect collagen-binding specificity and surface polymerization as well as the virulence potential of the YadA protein of Yersinia enterocolitica. Mol Microbiol 10, 995-1011.

Welkos, S. L., Friedlander, A. M. \& Davis, K. J. (1997). Studies on the role of plasminogen activator in systemic infection by virulent Yersinia pestis strain C092. Microb Pathog 23, 211-223.

Yang, Y. \& Isberg, R. (1993). Cellular internalization in the absence of invasin expression is promoted by the Yersinia pseudotuberculosis yadA product. Infect Immun 61, 3907-3913.

Yang, Y., Merriam, J., Mueller, J. \& Isberg, R. (1996). The psa locus is responsible for thermoinducible binding of Yersinia pseudotuberculosis to cultured cells. Infect Immun 64, 2483-2489.

Yen, Y. T., Karkal, A., Bhattacharya, M., Fernandez, R. C. \& Stathopoulos, C. (2007). Identification and characterization of autotransporter proteins of Yersinia pestis KIM. Mol Membr Biol 24, $28-40$.

Yu, D., Ellis, H. M., Lee, E.-C., Jenkins, N. A., Copeland, N. G. \& Court, D. L. (2000). An efficient recombination system for chromosome engineering in Escherichia coli. Proc Natl Acad Sci U S A 97, $5978-5983$.

Edited by: P. van der Ley 